\title{
Ocean Climate Monitoring
}

\author{
Rick Cole ${ }^{1 *}$, Jeff Kinder ${ }^{2}$, Weidong Yu ${ }^{3}$, Chun Lin Ning ${ }^{3}$, Fujun Wang ${ }^{4}$ and Yang Chao ${ }^{5}$ \\ ${ }^{1}$ RDSEA International, Inc., St. Pete Beach, FL, United States, ${ }^{2}$ Down East Instrumentation, LLC, Parish, FL, United States, \\ ${ }^{3}$ State Oceanic Administration, First Institute of Oceanography, Qingdao, China, ${ }^{4}$ Institute of Oceanology, Chinese Academy \\ of Sciences, Qingdao, China, ${ }^{5}$ Proteus Solutions, Beijing, China
}

Measuring ocean physics and atmospheric conditions at the sea-surface has been taking place for decades in our world's oceans. Enhancing R\&D technologies developed in Federal and academic institutions and laboratories such as WHOl's Vector Averaging Current Meter (VACM, 1970s) and NOAA - PMEL's: Autonomous Temperature Line Acquisition System (ATLAS, 1980s) as example, in situ ocean measurements and realtime telemetry for data processing and dissemination from remote areas of oceans and seas are now common place. A transition of this "ocean monitoring" technology has occurred with additional support from individual and group innovative efforts in the field of ocean instrumentation. As a result, long-term monitoring of ocean processes and changes has become more accessible to the research community at large. Here; we discuss a "Hybrid" air-sea interaction deep-sea monitoring system that has been developed in the private sector to mirror ocean-climate community data streams and has been successfully deployed on three basin-scaled programs in the Indian Ocean (RAMA, First Institute of Oceanography, FIO, China), the Andaman Sea (MOMSEI, Monsoon Onset Monitoring, FIO) and the Pacific Ocean (China's Institute of Oceanology, Academy of Sciences (IOCAS) research in the western tropical Pacific). This application is a base to build upon as new sensors are developed and increased sampling at higher resolutions is required. Surface vehicles measure the surface, with some profiling available. Water column density sampling is still a much-needed measurement within the Ocean Climate Monitoring community. The "Hybrid" is a multidisciplinary tool to integrate new biological and biogeochemical sensors for continued interaction studies of the physical processes of our oceans. This application can also be used at FLUX sites to enhance the Argo Program, telemetry applications and docking stations for autonomous vehicles such as sail-drones, gliders and wave riders for enhancement and contribution to the Global Tropical Moored Buoy Array (GTMBA), Global Ocean Observing System (GOOS), Global Climate Observing System (GCOS), and the Global Earth Observing System of Systems (GEOS).

Keywords: density, $\mathrm{CO}_{2}$, ocean temperature, ocean currents measurement, ocean physics

\section{INTRODUCTION}

With the Ocean Climate Monitoring community, worldwide, now settled into a "relaxed funding stage," the future of ocean observing is taking shape and continues to evolve. Technology driven change is occurring, with a mutual goal: continue and increase gathering critical information on how the world's oceans interact with each other along with peripheral terrestrial ecosystems. Oceanographers and Atmospheric scientists must engage in long-term ocean measurements to 
piece together the physical structure of the surface and subsurface below. Understanding physical processes such as air-sea interaction, heat and momentum exchange, freshwater movement, changes in temperature and salinity (density), velocity and direction of major current flow and their spin off eddies along with ocean acidification characteristics are considered the basics. The tools and capabilities for measuring these parameters are forever evolving. New Satellite systems with higher resolutions, automation, micro-electrical-mechanical (MEMS) sensors and even artificial intelligence (AI) are becoming standard and set to be used at length in the coming decades of ocean observation.

Three large multinational programs have set the tone for basin-scale ocean observing systems including; "The Tropical Atmosphere Ocean/Triangle Trans-Ocean Buoy Network" (TAO/TRITON, Pacific), "The Prediction and Research Moored Array in the Tropical Atlantic" (PIRATA), and "The Research Moored Array for the African-Asian-Australian Monsoon Analysis and Prediction Program" (RAMA; McPhaden et al., 2009) a subcomponent of the "Indian Ocean Observing System" (IndOOS). All are components of the "Global Tropical Moored Buoy Array" (GTMBA) and systems within a system; the "Global Ocean Observing System" (GOOS).

Tropical Atmosphere Ocean, formerly the "Tropical Ocean Global Atmosphere" program (TOGA) and the "Equatorial Pacific Ocean Climate Studies" (EPOCS) of the 1970s and $80 \mathrm{~s}$, is now a well-established operational program. PIRATA, still in research mode, covers the tropical region of the Atlantic Ocean. RAMA is the youngest of the arrays with emphasis on the role of the ocean for prediction of the Asian Monsoon, Indian Ocean Dipole (IOD) and El Niño/La Niña-Southern Oscillation (ENSO), all contributing factors to global climate. Buoy monitoring systems deployed in these regions take a "snap shot" of ocean climate as it changes over time creating basin-wide time series. Smaller spin-off programs collecting high resolution data, in the coastal-boundary regions have added additional data sets for model integration. Two key-words above; "Buoy monitoring" are a focus of a transition to less fixed-point assets on programs (i.e., anchored buoy systems) to a more automated configuration, taking advantage of new technologies, both satellite and in situ, with the goal of increased efficiency yet maintaining data quality.

The IndOOS and RAMA Programs now close the longstanding gap in data between the three major Oceans. This research also benefits many outside the Indian Ocean (IO) region due to the atmospheric connections that influence surrounding nations. Additionally, these data will contribute to improve forecasting of tropical cyclones and storm surge. Continued science and technology transfer to the IO-Rim countries helps establish observing capabilities in the region and to promote programs to better understand their role in the global climate system. China's State Oceanic Administration (SOA), First Institute of Oceanography (FIO) has engaged in field operations and data support to the RAMA array, occupying two locations in the eastern region of the tropical IO. These sites help capture the first signal from the western Pacific via the "Indonesian Throughflow" into the IO monitoring array.

First Institute of Oceanography is also deployed on the Monsoon Onset Monitoring and its Social and Ecosystem Impact (SEAGOOS-MOMSEI), a program set to improve the understanding and forecasting of the Asia monsoon and its multi-scaled variability within the Andaman Sea, west of Thailand, a common boundary region in the eastern IO and Bay of Bengal (monsoon behavior and coral reef bleaching). The Institute of Oceanology, Chinese Academy of Sciences (IOCAS, Qingdao, China) has expanded their monitoring program in the north to the tropical western Pacific with increased data collection throughout the region. With the loss of sites in the south (i.e., funding), the Japan Agency for Marine-Earth Science and Technology (JAMSTEC) Triangle Trans Ocean Buoy Network (TRITON) data streams have decreased, leaving gaps in model input. JAMSTEC collaborates with NOAA-PMEL on the TAO/TRITION array. IOCAS hopes to regain some of these data sets in the future by re-populating critical locations along this Equatorial region.

RDSEA International (St Pete Beach, FL, United States) and Down East Instrumentation (Parish, FL, United States), CoAuthors on this writing, have a vast background in oceanobserving, systems integration and data dissemination on U.S. Federal and State programs over many decades, some mentioned above. One of their goals as a team was to develop and mirror a deep-water monitoring buoy and mooring system such as the U.S. National Oceanographic and Atmospheric Administration (NOAA), Pacific Marine Environment Laboratory (PMEL), Automated Temperature Line Acquisition System (ATLAS; Milburn and McLain, 1986), with available, present day, Original Equipment Manufacturer (OEM, off the shelf) components. This goal was achieved with the collaborative efforts of the FIO and IOCAS in Qingdao, China, and Proteus Solutions, Hong Kong, in the Indian and Pacific Oceans. This support has contributed successful technology transfer to our colleagues in China and Southeast Asia (Indonesia and Thailand) with data streaming now for nearly a decade. New laboratories have been populated to receive, process, and disseminate data expanding needed input to the ever-challenging task of monitoring the changing dynamics of the tropical ocean.

\section{SYSTEM BACKGROUND}

In the early 1980s, the National Oceanic and Atmospheric Administration's (NOAA) Pacific Marine Environmental Laboratory (PMEL) began development of an inexpensive buoy and mooring system called the "Autonomous Temperature Line Acquisition System” (ATLAS; Milburn and McLain, 1986). These efforts paralleled one of the most significant ENSO events ever to take place in the Pacific (El Niño, 1982-83). ATLAS measures basic parameters at the sea surface including wind speed and direction, air and sea surface temperature. Ten subsurface locations record temperature at various depths down to 500 meters with redundant pressure recorders at the bottom of the 
string. These data are then sent to shore using the ARGOS telemetry system based on NOAA polar-orbiting satellites (data are also recorded onboard in memory).

The ATLAS system was based on earlier designs used at PMEL on current meter projects (McPhaden, 1995) and would be used to enhance studies on the thermal structure of the upper water column, wind-fields and the transport of heat in the tropical regions of the Pacific Ocean (i.e., airsea interaction). From the few initial deployments, ATLAS was quickly incorporated into the "Tropical Ocean Global Atmosphere" program (TOGA, Hayes et al., 1991) which was initiated to better understand ENSO phenomenon via realtime oceanographic measurements. TOGA laid the foundation for what is in place today; The Tropical Atmosphere Ocean (TAO) program, an array of 70-plus buoys and moorings spanning the equatorial region of the Pacific between $8^{\circ} \mathrm{N}$ latitude and $8^{\circ} \mathrm{S}$ latitude. The Japan Agency for Marine-EarthScience and Technology (JAMSTEC) maintains and manages the western component of the array with their TRITON (similar to ATLAS) buoy systems.

Autonomous Temperature Line Acquisition System electronics (designed and manufactured at PMEL) were completely re-engineered in the early to mid-1990s with new sensors added (relative humidity, radiation, precipitation at the surface and conductivity at depth) (Milburn et al., 1996). The initial systems design of bringing sub-surface temperature data up to the buoy used a thermistor string with temperature pod breakouts at the following depths: $20,40,60,80,100$, $120,140,180,300$, and 500 meters in the eastern Pacific and $25,50,75,100,125,150,200,250,300$, and 500 meters at western locations. Pressure is also measured at the bottom of each string at the 300 - and 500-meter levels. These data are used to monitor mooring motion and allow for depth corrections in post processing of temperature data. Subsurface data telemetry to the buoy was replaced by the process of "induction" allowing for simple attachment of sensors using inductively coupled components to the main mooring line and sending a signal (data) up to the buoy controller. Wind speed and direction are measured at 4 meters above the sea surface at $2 \mathrm{~Hz}$ along with a thermistor mounted in a radiation shield to reduce the effects of solar heating for air temperature records. Sea-surface temperature is also measured at a depth of 1 meter.

RDSEA, in partnership with Down East Instrumentation, began a system's engineering approach using the TAO Legacy ATLAS System among other coastal buoy system designs as a baseline for hardware, instrumentation and sample rates. Having been involved in similar design concepts with NOAA and academia using "off-the-shelf" sensors and equipment, we believed it was possible to mirror TAO type buoys and their data streams using existing OEM instrumentation and components.

\section{THE BUOY SYSTEM}

Requested from colleagues at FIO and IOCAS was delivery of real-time data acquisition buoy and mooring systems consisting of a full suite of meteorology (MET) at the sea surface, conductivity, temperature and pressure (CTD) throughout the water column to a depth of 700 meters along with current velocity and direction in the upper $100 \mathrm{~m}$. Project goals were to provide complete turn-key oceanographic buoy and mooring systems for deployment on RAMA. The design would be consistent with ongoing mooredbuoy programs within the GTMBA (Thurston, 2019). All instrumentation and electronic components used are standard "off-the-shelf" ocean instruments proven in the field to provide scientific quality data with long-term durability. All data, surface and subsurface, are transmitted in near realtime and follow standard software and data collection format configurations. A "taut-line" mooring was chosen due to its" proven success throughout decades of robust, long-term use in the deep ocean.

\section{THE BUOY}

A wave following hull design (double chine) of thick walled, closed-cell structure ionomer foam (Softlite Surlyn ${ }^{\circledR}$ ) was chosen for all applications. Many research groups have achieved success with this product on both blue water and coastal programs. For our deployments in over 5000 meters depth a 2.3-meter diameter hull with a nominal density of $8,580 \mathrm{lbs}$. (buoyancy) was developed.

\section{THE MOORING}

The "taut-line" mooring design dates' back to the early configurations used at the Woods Hole Oceanographic Institution (WHOI) on buoy projects and is the mooring of choice on programs throughout the GTMBA. This design is well proven, relatively easy to deploy and recover with the proper deck gear aboard ship and may be redeployed again on the same research cruise. The philosophy behind a taut-line mooring is to cut the nylon shorter than the deployment site depth (0.985 scope) allowing the elongation factor of the nylon to keep the mooring "taut." All instruments then take measurements at their actual deployed depths (i.e., locations along the mooring line). The buoy system is designed to lift the mooring and anchor during events of heavy seas once maximum stretch is achieved in the nylon, preventing the buoy from sinking. A back up positioning beacon is installed separately (position only) to monitor this buoy movement across the sea-surface.

\section{THE “INDUCTION" PROCESS}

Until recently, sub-surface ocean instrumentation had to be directly cabled to the surface for the transfer of data (as in the ATLAS Legacy System). This is a weak-link in mooring ocean instrumentation and usually the first line of data loss due to cable fatigue and failure. As technology advanced, the use of 
cabled sub-surface sensors at depth on moorings has diminished. Using the jacketed wire rope as a conduit for data transfer, an inductive modem mounted internally on instruments attached to the mooring line transfers signals to a buoy controller at the surface (McPhaden et al., 2016). These instruments include an integrated coupler (magnet) made up of two halves attached externally, allowing them to simply clamp around the mooring. Swaged fittings at both ends of the mooring cable form the seawater-ground needed to complete the inductive loop through the cable. This induces a signal in the single-turn secondary winding formed by the mooring cable passing through the coupler. Data is received from depth via an inductive cable coupler (ICC) that clamps onto the wire rope just below the buoy and mooring attachment (clevis) and is then cabled up to the buoy controller where the sub-surface signal (data) from each instrument is received, decoded and processed.

\section{SYSTEM PAYLOAD}

The buoy system maintains a suite of atmospheric sensors: air temperature, wind (speed and direction), barometric pressure, relative humidity, precipitation, short and long wave solar radiation. Additionally, the system collects near real-time data inductively from sub-surface instruments: SBE37 MicroCats measuring temperature and conductivity, SBE-39 temperature recorders measuring temperature including pressure sensors, and single point Doppler Volume Samplers (DVS, current speed and velocity). A GPS receiver is used to track the position of the buoy and sync the data logger/controller clock with Universal Coordinated Time (UTC). A redundant satellite communications system (dual modems) is used for near real-time telemetry of all data collected via the Iridium satellite constellation. The controller is responsible for scheduling when the sensors will begin sampling, calculating averages, storing information from the sensors in data files and outputting the data records to the satellite modem. When the controller is not performing any of these functions, it reverts to a low power sleep state until the next scheduled sample is to be taken. This is done to conserve systems power as much as possible. The system is designed to be a turn-key, self-contained control and logging application (Figure 1). The Supplementary Data Sheet S1 displays the entire system design.

Additional sensors are presently being added to monitoring arrays and data streams from our world's oceans and the large basin-scale programs. Understanding the partial pressure of $\mathrm{CO}_{2}\left(\mathrm{pCO}_{2}\right)$ at the sea-surface is critical for monitoring ocean acidification levels and the effects and consequences $\mathrm{CO}_{2}$ emissions have on offshore and terrestrial ecosystems. Incorporating these sensors and beginning time-series along with measuring $\mathrm{pH}$, dissolved oxygen, turbidity and chlorophyll will help the ocean sciences better understand the changes in sea-water chemistry as it occurs. In the spring of $2011 \mathrm{CO}_{2}$ measurements were added to the FIO RAMA buoy at a depth

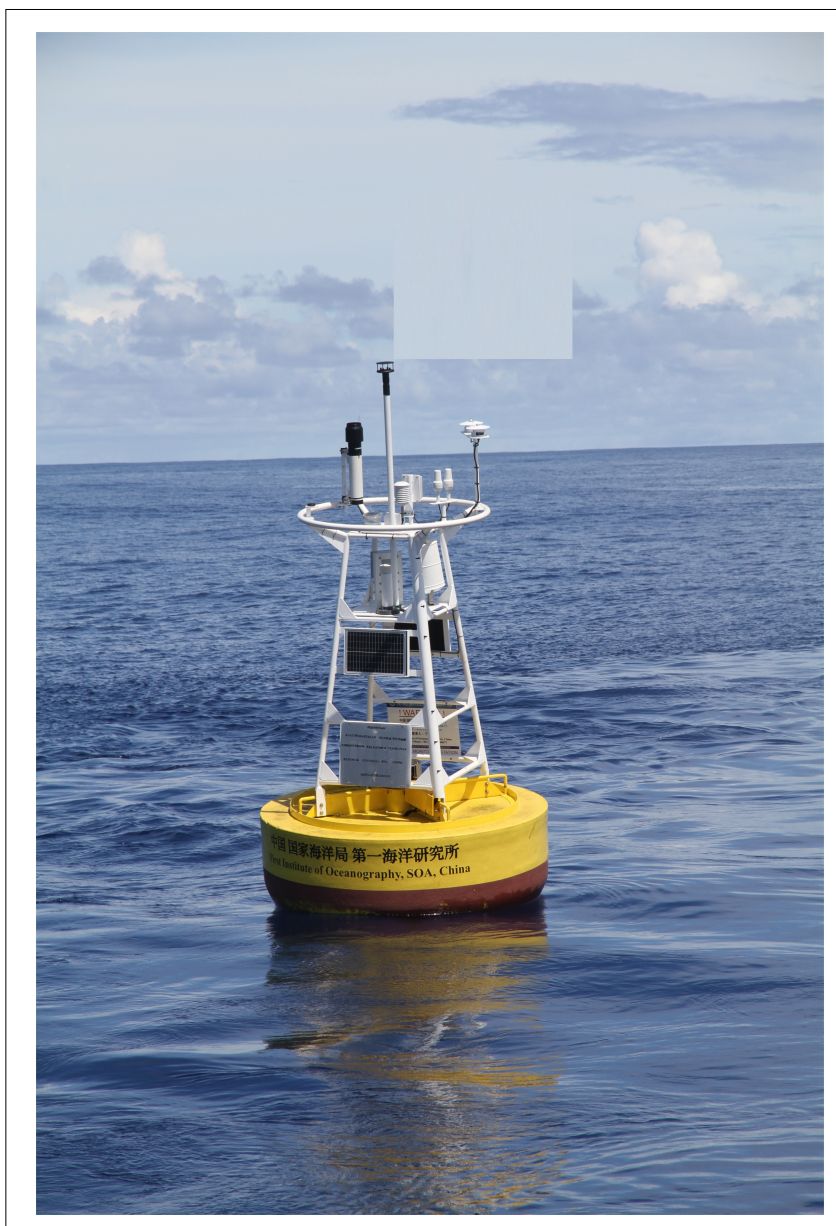

FIGURE 1 | Deployed system, RAMA - Indian Ocean.

of one meter (sea-surface) and on the tower (atmospheric), the first on RAMA.

\section{CONCLUSION}

The development of an "off-the-shelf" deep water buoy system, mimicking the NOAA-TAO-ATLAS design of the 80s and 90s has been tested and deployed. The framework to enhance upon this design has been laid with new ideas in motion for the future longevity of ocean climate monitoring sites. Fixed monitoring sites are still needed on the GTMBA programs, especially for collecting critical wind and density data at FLUX locations. A multinational redesign is well underway (Tropical Pacific Observing System, TPOS-2020; Cravatte et al., 2016), taking advantage of new ocean observing technologies to maintain and extend the tropical ocean climate record. A combination of buoys and moorings plus automated in situ devices such as; gliders, water column samplers (ARGO Program), surface wave riders and sail-drones enhance the needs of the community. RDSEA and Down East Instrumentation 
will continue to support these efforts, buoy system assets and programs and continue to work at sustaining the data flow from present and future locations. Plans for adding additional sensors such as dissolved oxygen and fluorescence are in discussion with hopes of integration and deployment in the very near future.

\section{AUTHOR CONTRIBUTIONS}

All authors listed have made a substantial, direct and intellectual contribution to the work, and approved it for publication.

\section{FUNDING}

This work was supported by the First Institute of Oceanography, State Oceanic Administration and Institute of Oceanology Chinese Academy of Sciences (IOCAS).

\section{REFERENCES}

Cravatte, S., Kessler, W. S., Smith, N., Wijffels, S. E., Ando, K., and Cronin, M. (2016). First Report of TPOS 2020. GOOS-215-200. Available at: http://tpos2020. org/first-report (accessed October, 2018).

Hayes, S. P., Mangum, L. J., Picaut, J., Sumi, A., and Takeuchi, K. (1991). TOGATAO: a moored array for real-time measurements in the tropical Pacific Ocean. Bull. Am. Meteorol. Soc. 72, 339-347. doi: 10.1175/1520-0477(1991)072<0339: ttamaf $>2.0 . \mathrm{co} ; 2$

McPhaden, M. J. (1995). The tropical atmosphere ocean array is completed. Bull. Am. Meteorol. Soc. 76, 739-741.

McPhaden, M. J., Ando, K., Bourlès, K. B., Freitag, H. P., Lumpkin, R., Masumoto, Y., et al. (2016). Real-Time Oceanography with Inductive Moorings and the Inductive Modem Module, (Application Note 92). Bellevue, WA: Sea-Bird Electronics, Inc.

McPhaden, M. J., Meyers, G., Ando, K., Masumoto, Y., Murty, V. S. N., Ravichandran, M., et al. (2009). RAMA - the research moored array for African-Asian-Australian monsoon analysis and prediction. Bull. Am. Meteorol. Soc. 90, 459-480. doi: 10.1175/2008bams 2608.1

Milburn, H. B., and McLain, P. D. (1986). "ATLAS-A low cost satellite data telemetry mooring developed for NOAA's Climate Research Mission," in Proceedings from MTS Marine Data Systems, New Orleans, LA.

\section{ACKNOWLEDGMENTS}

The authors would like to thank the individual and group efforts and contributions at all levels that have made possible the multiple successes of collaborative efforts over the past decade, including FIO and IOCAS staff, scientists, engineers, technicians and students, manufactures, and federal agencies from China, Indonesia and the U.S. Mooring Systems, Inc., of Cape Cod, MA, United States played a huge role in the success of these projects.

\section{SUPPLEMENTARY MATERIAL}

The Supplementary Material for this article can be found online at: https://www.frontiersin.org/articles/10.3389/fmars. 2019.00503/full\#supplementary-material

DATA SHEET S1 | Hybrid-ocean climate monitoring system mooring design.

Milburn, H. B., McLain, P. D., and Meinig, C. (1996). “ATLAS buoy-reengineered for the next decade," in Proceedings of IEEE/MTS Oceans '96 (Fort Lauderdale, FL: NOAA, Pacific Marine Environmental Laboratory), 698-702.

Thurston, S. (2019). The Tropical Atmosphere Ocean (TAO) Array Expands into Indian Ocean. Seattle, WA: NOAA Office of Climate Observation.

Conflict of Interest Statement: RC (RDSEA International) and JK (Down East Instrumentation) were employed/contracted by Chinese Academic Institutions: First Institute of Oceanography (FIO) and the Institute of Oceanology and Academy of Sciences (IOCAS) for this work. YC of Proteus Solutions, Beijing, China is the agent representing all foreign entities on all FIO and IOCAS projects via China and United States representatives.

The remaining authors declare that the research was conducted in the absence of any commercial or financial relationships that could be construed as a potential conflict of interest.

Copyright (c) 2019 Cole, Kinder, Yu, Ning, Wang and Chao. This is an open-access article distributed under the terms of the Creative Commons Attribution License (CC BY). The use, distribution or reproduction in other forums is permitted, provided the original author(s) and the copyright owner(s) are credited and that the original publication in this journal is cited, in accordance with accepted academic practice. No use, distribution or reproduction is permitted which does not comply with these terms. 